\title{
METAPHORS OF TRANSFORMATION OF EDUCATION AND FITNESS FOR PURPOSE: TOWARDS A HUMANIZING AGENDA
}

\author{
Y. Rodny-Gumede \\ School of Communication \\ University of Johannesburg \\ Johannesburg, South Africa \\ e-mail: yrodny-gumede@uj.ac.za \\ C. T. Chasi \\ Department of Communication Studies \\ University of the Free State \\ Bloemfontein, South Africa \\ e-mail: chasict@ufs.ac.za
}

\section{ABSTRACT}

Education is metaphorically tied to transformation. We apply this understanding to postcolonial and post-apartheid South Africa, noting that, as far as we know, no one has commented on the curious "doubling down" on the idea of change that is revealed by the conceptual contiguity evident in the construct "transformation of education". While we do not conduct a metaphor analysis of transformation of education, we nevertheless draw on elements and concepts from such analysis to discern meanings from what we term "compound conceptual metaphors" that frame discourses around transformation and education. We specifically discuss how the compound metaphor "transformation of education" is linked to the metaphor of "fitness for purpose". This directs us to new understandings of the work that the word "transformation" does in talk of "transformation of education" and in contestations over the meanings ascribed to "fitness for purposes". This goes to show how such understandings can chart a way for a humanizing transformation agenda.

Keywords: metaphors, transformation, education, fitness for purpose, decolonisation, South Africa

\section{INTRODUCTION}

In this article we engage with the metaphor of "transformation" in higher education. We note that the word transformation has meanings relating to change, variation, mutation or modification in the state of something. It is a word that has been used as a "catch all" metaphor for change in formations, regimentations or orderings in post-apartheid South Africa. Among other examples, ending the legacies of colonialism and of apartheid is described as transformation. So too transformation is a word used to describe gradual processes of integration that bring blacks, whites, women and men, etc. into new forms of cooperative 
existence that apartheid and colonialism previously prevented in a wide variety of spheres, education included.

We note that education is replete with metaphors that describe and shape it. Education has for instance been described as a process that "opens doors", schools are called "gardens of knowledge". Universities are described as "ivory towers", what is taught is termed "fruits of knowledge". Teaching and learning are indeed thought of, and associated with, metaphors borrowed from various disciplines, as seen in examples from, business (so learners become clients in monetized managerialist education system), the arts (with gifted students and teachers who act as muses), cooking (so that ideas stew in lectures and new knowledge is brewed over time), and gardening (with schools as nurseries of young minds ...) to name but a few. Metaphors are of course also often used as a teaching practice and a didactic and methodological tool.

It should not surprise that metaphors have such rich relevance to education. Metaphors are powerful linguistic devices and education is a foundational social project, rooted in language use for the transfer/sharing of ideas - without which human culture itself would not be possible. Increasingly, academics, students, university leadership and policy makers are embracing the need to think through a broad swathe of transformation issues. And, while metaphors can capture a wide gamut of meanings, they can equally become empty phrases and "stand ins" for real engagements with difficult concepts needing clarification, deliberation and articulation to be fully comprehended. ${ }^{1}$ Our contention is that thinking about transformation of education is remiss if it fails to recognise how metaphors guide and ground meanings, particularly with regards to renewed decolonisation debates in higher education.

As such we discuss how education is metaphorically tied to transformation in postcolonial and post-apartheid South Africa. As far as we know, no one has commented on the curious "doubling down" or "conceptual tautology" in the construct transformation of education. ${ }^{2}$ Inspired by the work done on metaphor analysis and the role that metaphors play in human cognition (cf. Lakoff and Johnson 1980), we ask what meanings can be discerned from, and given to, the word transformation in South African debates around transformation of higher education? We do so recognising that "transformation of education" can best be described as a compound conceptual metaphor. In the metaphor, transformation of education, for example, one can reasonably place either transformation or education as the source or as target domains though it is apparent that the two conceptual metaphors are mapping onto each other - i.e. they correspond with each other in compounded ways that yield new, extended or deeper meanings.

Further to this, we also show how the metaphor of transformation of education has been associated with, and given direction through, the sometimes quoted, but more often implied, 
metaphor of "fitness for purpose/s" which we present as a synecdoche for ideas to do with metaphors such as "fit for employment" or "fit for further training" or "fit for retraining", etc., used to equate quality with the meeting of specific needs ${ }^{3}-$ as is discussed, for example, in the Cultural Charter for Africa (Organisation of African Unity 1976) which ties building educational systems that work towards needing political, economic, social, depersonalizing and alienating practices and legacies of colonial and apartheid.

The two compound metaphor clusters of "transformation of education" and "fitness for purpose/s" correspond in the ways strategies and actions for the transformation of education can be developed to ensure education that is fit for meeting requisite skills related to varying socio-economic needs and to ensure an educational experience not only fit for purpose but that ensures academic success. Recognising this, we set out to contribute new insights into how the two "compound conceptual metaphors", 4 of "transformation of education" and "fitness for purposes" can be linked in higher education transformation debates in the interest of charting a way for a humanizing transformation agenda.

\section{EDUCATION AND TRANSFORMATION DEBATES IN SOUTH AFRICA}

Education is fundamental to human cultural evolution because of the ways in which it is attached to human agency, human communication and hence to how people get on with their lives. ${ }^{5}$ This is no more evident than through the recent calls in South Africa for a decolonisation ${ }^{6}$ of higher education.

Beginning in 2015 a wave of protests against the colonial and apartheid legacy arose at universities in South Africa. ${ }^{7}$ Key among the demands were calls for the removal of financial and language barriers to entry into the university system, cultural transformation to end colonial legacies of black marginalization, and demands for a decolonisation of the curriculum. Much of what was raised in the protests could be anticipated by anyone who followed discussions concerning transformation in higher education in South Africa. The need for transformation had already been recognized and outlined in the Education White Paper of 1997 that proposed a range of initiatives to transform the sector (Department of Education 1997). This was reaffirmed in the 2013 South African Department of Higher Education White paper for postschool education and training, however this time with "transformation" substituted by "redress" and "development" (Department of Higher Education and Training 2013, 5). Equally, the ideas of "fitness for purpose" have been emphasised in policy documents, and the Council on Higher Education states that:

"In relation to teaching, learning, research and community service, quality will be determined on 
the basis of the ability of the provider to offer qualifications, programmes and learning experiences which are responsive to the broad development needs of learners, thereby also addressing the knowledge, skills and service needs of the country at large. The criteria indicated above will be located within a fitness of purpose framework based on national goals, priorities and targets." (Council on Higher Education 2004, 9, authors emphasis).

The idea that transformation of education challenges foundational norms, networks, policies, cultures and structures is important. Drawing on Kalyvas' $(2008,227)$ reading of philosopher, Hannah Arendt, we think that the metaphor of the "foundational" suggests a kind of beginning, a form of transformation that cannot be countenanced without a world that already exists in advance. We hence recognise that we cannot think of transformation without also thinking about questions of "transformation from what to what", and what the metaphorical work the idea of transformation does when people speak of "transformation of education"?

\section{METAPHOR AND TRANSFORMATION}

Metaphor is fundamental to how people use language. A metaphor is a way of thinking about, conceptualizing and making sense of the world (Lakoff and Johnson 1980, 232-233). As such metaphor analysis becomes a way for analysing social and cultural processes of understanding (Moser 2000, 5), the meanings and assumptions they carry and the actions they might drive (Bullough and Gitlin 1995; Bullough 1991).

Conceptual metaphors, as Kövecses $(2015,4)$ notes, complexly pair clusters of organized conceptual experiences. Transformation is a conceptual metaphor that spatially relates education to conceptually complex "before" and "after" states. The before and after states here are complex and highly abstract even though they have concrete consequences in terms of how people act and live. Before is marked by apartheid and colonialism systems that in the thinking of Fanon $(1963,52)$ - are no more than different names for divisions of the Manichean colonial world. After is instead marked by democracy and developments that seek to deliver social justice to all. In South Africa people regularly speak of transformation of education as upending the inequity and injustice that forms, fills, and produces processes and structures by which colonial and apartheid patterns continue to direct, influence and benefit from the inherent unjust structures of higher education in South Africa.

Colonial and apartheid rule "eliminated all distinction between ends and means" so that "right was on the one side ... seized in the very act of occurring" (Mbembe 2015, 26) with the consequence that in postcolonial arrangements excellence resides still in the fact of something being on the side of the instantiation or production and reproduction of the colonial and apartheid project. For this reason, Makgoba and Seepe $(2004,15)$ are insightful when they say: 
"Complacency and mediocrity set in as soon as universities declare themselves custodians rather than seekers of knowledge and excellence - as some do in [South Africa]". The suggestion is that to end colonial apartheid malformations of the idea of excellence in education is to allow and to drive these misanthropic systems towards a kind of death. Epistemicide of colonial and apartheid orders is necessary if we are to enable practices of a democratic and just education system to be resurrected in their place (cf. Chasi 2015, 181).

What is problematic about colonial and apartheid systems is that they make crude simplifications such as race the basis for the articulation of truth and excellence whether in art, science, philosophy or in legal and governance practices. Under these misanthropic systems these crude beginnings become the basis for supposedly advanced productions of "right ... on the one side" (Mbembe 2015,26) with the consequence that the "daily and hourly scrutinizing" that Darwin $(2009,66)$ saw as fundamental to adaption and evolution are adumbrated or stunted through complex, sophisticated processing that nevertheless does not leave their simple, bare, visible and half-monstrous beginnings as stereotypes that essentialize and deny a complex and shared humanity.

The quest for transformation of higher education - to end apartheid and colonial legacies, requires recognition that all human cultural activity involves communicative enactment of common grounds and norms on which people construe and act out approximations of the good, safe and desirable. Transformed education is in contrast with construals and practices that wrongfully take the "different or strange" to be bad, evil, deviant, harmful or dangerous. Especially where gross differences or strangeness are visible or foregrounded by feelings of being threatened by "out-groups", the reaction is often towards what communication accommodation theory calls divergence (Gallois and Callan 1991, 264). However, separating people into "in" and "out" groups is not what distinguishes apartheid societies from others.

Instead, apartheid is misanthropic in the ways it paradigmatically attacks what Tomasello (2010) has called the uniquely human capacity for altruism, i.e. the basis for how humans are uniquely informative, sharing and giving in ways that allow unique human communication and culture. Thus, albeit pejoratively, in everyday situations one hears agreement that anything that diminishes a person's ability to demonstrate altruism, culture or communication is an attack on the afflicted individual's humanity. In attacking the possibility for human communication and culture, apartheid attacks the fundamental possibilities that shape the form and function of education and the university - this importantly explains why colonialism and apartheid are antithetical to excellence in education. Thus, the project of transforming higher education by ending the legacies of colonialism and apartheid is quite simply indispensable to any endeavour to achieve education that is not misconstrued as miss-education or not "fit for purpose". 
The following section ventures to illustratively discuss some metaphorical formations that talk of transformation of higher education powerfully calls to mind and how these are linked to ideas of "fitness for purposes". We importantly discuss how the metaphor clusters of both transformation of education and fitness of purposes can be linked in the interest of setting out a transformation agenda based on humanizing development. ${ }^{9}$

\section{THE METAPHOR OF "FITNESS" IN "TRANSFORMATION OF EDUCATION"}

In higher education the metaphor of "fitness for purpose" speaks to debates around the ability of universities to produce graduates with the requisite skills to serve various sectors of the economy, and as stated earlier, in ensuring an overall learning environment that promotes and facilitates academic excellence. In the context of South Africa and in the light of calls for a radical transformation of higher education with the view to break with inherent colonial legacies, such debates ultimately concern the relevance of curricula for the social, political, cultural and economic context that it serves, and importantly how to restructure higher education to ensure diversity, inclusivity, and redress.

Discussing the metaphor of fitness for purpose is useful because it enables us to see complex interplays of metaphors marshalled by use of the compound conceptual metaphor transformation of education. In the compound of conceptual metaphors, transformation and education intersect in a dizzying multiplicity of ways and in light of calls for a decolonisation of education such meanings are often contested and rarely analysed for their underlying assumed meanings.

Our point with idea of the compound conceptual metaphor is that an expression such as transformation of education is composed of two conceptual metaphors that are equally abstract and that "double-down" to constitute a new, deeper or extended meaning. In this instance the meaning of transformation of education is seemingly "doubling-down" on the idea of a change that is revealed by the conceptual tautology or contiguity that is evident in the construct of transformation of education. Because the metaphors of transformation and education can act as both source and target, sometimes the "doubling down" that is entailed also accentuates difficulties that face people who seek narrow, easy and straightforward engagements with the difficult, messy and complicated business of the transformation of education.

Thus, to give concrete meaning and action to transformation of education, people sometimes speak of seeking "fitness" or "fitness for purpose/s". The metaphor of fitness used to illustrate optimization and relatedness of two or more things, vividly presents a visual impression of an instrumentalist university/educational enterprise that achieves key functions within the places and spaces in which it belongs. 
Attendant attempts to see if the university is "fit-for-purpose" go towards examining the statements of the purposes of a university. ${ }^{10}$ Key statements of interest in this regard are typically available in vision; mission; strategy; budgeting documents; regulations of entry, exit, and merit; as well as in statements of qualification mixes and curricula. These statements are however also spelt out in institutional practices by which actions are acted out, legitimated, secured, disciplined, punished, incentivized, normalized and made irrelevant and/or meaningful. Those who deliberate on the statements of fitness for purpose that universities make, therefore often quickly establish that beyond the "formal" statements there are also "informal" ones that confusingly intersect with, and direct, by way of tradition and coconstructive practices, how transformation efforts produce and generally relate to meanings of fitness for purposes.

The metaphor of fitness is, in key respects, one that seeks a way to link transformation of education to concrete principles, practices and processes that refine, and even reject metaphors that express miraculous, instantaneous, "hypodermic needle", "magic bullet" or "single shot" change. The quest for a rich and appropriate metaphoric expression of the change that transformation can effect, entails finding metaphors that direct or stimulate actions towards multiplexed processes that over time yield new social forms that re-humanises where colonialism and apartheid dehumanised.

We therefore proceed to set out how the compound metaphors of transformation of education and fitness for purpose relate to each other within select core areas and functions of the university. We do this to show how we can ascribe new meanings to the connections these metaphors make in order to contribute to, and make concrete, a higher education transformation agenda that humanises where colonial and apartheid legacies continue to dehumanise.

\section{Fitness for transformation of principles, structures, practices and processes}

While, university mission statements, as set out above, do talk to both the direction of the university as well as the values embraced by the university, they often do not give explicit guidance to transformation agendas. Neither do they, in the context of South Africa and the post-merger universities, set out the beliefs or doctrines that have shaped the university prior to the mergers, i.e. the informal statements and principles of the university, and as such do little to articulate the details of a transformation agenda that seeks to find answers and solutions to the question of "transformation from what to what?"

Importantly, some of the work that agents of transformation in universities have started to do is to reduce the distance between the formal and the informal statements of purposes of the university. In this regard agents of transformation have often been interested in uncovering the 
hidden purposes, missions and visions, embedded in the policy frameworks of the university and their bearing on the core functions and practices of the university. Decolonisation debates have thus gone beyond calls for curricula transformation, a socially just curriculum and equity in staffing for example to also address and break with colonial and apartheid institutional cultures.

For mission statements to be effective as a transformation tool, they need to address the principles upon which transformation is premised and as such articulate the "before" and "after" as well as the "formal" and "informal" with great honesty and in great detail. As such, transformation practices and the ideas that ground them have to address everyday needs. However, this is not and should never be "an either or" scenario in which one groups' power or interpretive agenda is favoured over another. Likewise, the moral imperatives for change should not be juxtaposed against the need for addressing the technicalities of the "what" and "how". Instead, transformation efforts must be clear on addressing the practices entailed in effecting change in a manner that does not shun away from the moral imperatives for change premised on the "before" and that leads the way to the "after".

Therefore, and in order to understand the meanings of transformation as well as fitness for purpose in the context of practices, we first need to address the status quo of how "things are done" and how practices are sanctioned by colonial and apartheid legacies. Second, we need to consciously re-shape practices in ways that address every day realities and the challenges that the legacies of colonialism and apartheid have created. This independent of being practices aimed at transforming institutional cultures, communication, access, fees, staffing, curricula, pedagogy, teaching methodologies etc.

Further to this, for principles and practices to be functional and have meaning, they must be supported and informed by processes created to lead transformation in the immediate as well as long term. The word process is in and of itself a metaphor associated with change and transformation and refers to procedures and courses of actions that steer development and progression within the university. Processes thus are the methods that inform practices, activities and courses of action that lead and effects transformation in ways that goes beyond seeing transformation and a decolonization as mere agenda points for discussion.

Equally, and related to both principles, practices and processes, are the structures or system of parts that link functions within the organization of the university. For principles, practices and processes to be given meaning and implementation they have to be underpinned by structures that tangibly support the principles, practices and processes of a transformation agenda. This is most acutely felt through the lack of transformation in staffing. In this regard, it is worth asking whether adequate structures have been put in place to address equity within 
the university. And where attempts and programmes have been put in place for recruitment and the advancement of academic staff as well as well as non-academic and support staff from designated equity groups, the question to be raised is if these are not more examples of institutional cultures that reinforce ideas of supremacy and exclusion (cf. Luvalo 2019). Thus, fitness for transformation of principles, structures, practices and processes must also be evaluated on grounds of how they advantage or disadvantage a humanizing transformation agenda.

\section{Fitness for transformation of culture, communication and people}

The underlying structures of the university also inform institutional culture, organizational identity and identification. In essence, the university merger reform was implemented to address the bifurcation of higher education shaped by apartheid policies of separate education and well as seats of learning for different language and race groups. And through the mergers a new university was to be formed based on shared beliefs and values. The question is how far the mergers have been able to address these issues and to what extent the new institutions have been able to implement a transformation agenda that has cultivated a common culture based on shared beliefs, attitudes and adherence to practices that breaks with the colonial and apartheid past. And can transformation really be said to have been affected if a common culture is emphasized as the greater good and value judgments made about who's culture is deemed the superior?

With the incorporation of former black institutions of higher education into formerly white universities have come scenarios in which the "new" institutions have taken on the role of "benevolent hosts" of the historically underprivileged "black" universities and universities of technology creating big brother scenarios in which the "hosts" institutional culture, language of instruction has set the frame from which in the university functions and education is conducted. Thus, the new universities created by the mergers are interesting examples of continuing legacies of apartheid ideologies of white supremacy. Thus, institutional culture from a transformation perspective should rather put the emphasis on unity in diversity than ideas of a shared culture that still bears elements of exclusion.

If institutional cultures are to be transformed, communication as well as acts of communicating and the exchanging of information needs to be transformed. Communication is key to how people access the university, the rapport they form with the institution and people within the organization and most importantly sets the parameters for ascension and success within the university. Education and ideas of knowledge transfer and acquisition is premised on communication, and communication in and of itself a transformative practice often used as 
a means to institute change. Transformation debates in South Africa have however so far taken little heed of the role of communication. Communication is still thought of in very narrow terms as a practice of imparting and partaking of information, whether from within the context of the classroom or from internal as well as external organizational communication perspectives. Not only do we need to consider communication from a pure or technical language perspective and ideas of facilitating access to education and institutional support as well as the provision of tuition and learning materials in indigenous African languages, but also from perspectives of facilitating inter-cultural communication and changing institutional cultures to minimize exclusion and facilitating belonging.

Communication is also essential for the transformation of individuals. Education is itself premised on the idea of transforming individuals. Universities at their best is thought of as places where knowledge is not simply transferred from one individual to the other or knowledge acquisition necessarily the sole mission, instead, universities are thought to facilitate a broader transformation of people and the fostering of active citizenship. Colonial and apartheid education has done little in this regard. And equally, post-merger institutions have done little to facilitate a broader transformation of people. This said there are examples of the transformative role that communication can play, Pithouse-Morgan et. al. (2016) for example shows how poetry can be used to capture stories from academics, particularly younger colleagues entering the academy for the first time, to reflect and uncover ease and unease, in order to build collegial relationships and a new generation of academics.

We know that access to education can transform people's lives. In the context of postcolonial South Africa, as throughout the post-colonial world, having a higher education degree and in particular having a university degree is still an entry ticket to social up-liftment and a chance to transform and turn the clock back on centuries of disadvantage. Clearly education has a crucial role to fulfil in not only transforming people's lives but also in transforming people. The metaphors of education as "growth" and "sowing seeds" are intimately connected to the idea of effecting change in the individual. The question remains "what change" and on "whose" premises? If such change is premised on continuous fitness for purposes lodged in power structures and power imbalances and interpretative frameworks and ideas of racial supremacy, patriarchy, sexism or other forms of hegemonic power structures, change will be continuously premised on a uni-directional hegemonic colonial and apartheid idea of identity and of what constitutes "modernity", "civilization", "good and bad" "correctness" and "excellence".

Once again, these varying aspect of transformation and fitness for purpose can best be laid bare by looking at both the "before" and "after" as well as the "formal" and "informal" as to 
measure degrees of change from one state to another.

\section{Fitness for transformation of organizational resources and resource allocation}

The idea that transformation is something that can happen without direct intervention, conscious efforts and planned strategic action has largely been re-evaluated and even rejected through recent developments in the higher education landscape in South Africa and amidst renewed emphasis on the decolonization of higher education. In this regard resourcing is key to transformation. However, we do not here solely refer to resourcing of a transformation or decolonization "project". Instead, we make a point to highlight the inequities in how organizational resources are controlled and allocated. Organisational resources and resourcing talks to both tangible and intangible gains and institutional strives for competitive advantage. Resourcing and how resources are allocated to the broader transformation project as well as its constituent parts and stakeholders will largely determine the trajectory and success of processes of transformation and decolonization, in the immediate as well as long-term.

While many of the former white universities were often well funded and relied on both state funding and private endowments, the formerly black institutions to the contrary suffered from under funding and resources pledged to only maintain the bare basics of the apartheid ideas of separate education of the black population for purposes of maintaining a steady stream of semi-educated blacks for low-level, low-skilled professions.

With the university mergers came demands for equitable resource allocation and increased student enrolments and with the recent funding crisis in the higher education system in South Africa, resources are scares and planning needs even more acute. This as we know is also coupled to budget increases in university administration and debates on relative funding needs in and between academic disciplines. In this regard, both resources and resource allocation form a link between transformation of education and fitness for purposes. Importantly, "transformation" will have to be premised on resource allocation to a teaching project that is fit for the purpose of addressing equity and redress for students held back by current colonial and apartheid legacies as well as the development of a curricula that is "fit" for the context that it serves and in which graduates will furnish their lives.

Such "fitness for purpose" is also premised on how universities approach problems and innovation in its overall operations.

\section{Fitness for transformation of problem solution, innovation and organizational learning}

How organisations approach problem solution and innovation say a lot about an organisational 
orientation towards success. In this regard, it is commonly thought that solution orientated problem solving is driven by empowered individuals, individuals seen, valued and recognized for their contributions and that broad-based and cooperative decision-making forms the basis of successful implementation of change.

Transformation, in relation to education in the context of post-colonial South Africa and in light of intensified calls for the decolonization of higher education, could perceivably be seen as a "problem", a problem lodged in an opposition to or reluctance of change or a problem of inherited power imbalances. Thus, problem solving and innovation on a systemic level is often held back by a university structure, organization, structure and associated practices as well as processes premised on a reluctance to break down inherent power imbalances that discourage inclusiveness and broad-based decision-making.

In this context, transformation is seen as a battle of ideological standpoints with solutions thought to benefit one over the other. Equally, ideas of fitness for purpose is contested and often used as a means of discouraging change rather than to encourage it, with the result of limiting problem solution and innovation throughout the higher education system and in all its associated parts and functions.

This can, for example, be seen in the ways that organizational learning, knowledge creation and transfer is still lodged within an organizational set-up of inherent power imbalances. In a postcolonial context, and in the context of the South African university mergers, knowledge creation and transfers has been premised on a continuation on structures and practices inherited from the former white institutions. As such very little "new" or redefined knowledge creation has taken place within the new institutions formed. Thus, the calls for a decolonisation of the university are calls for new knowledge creation and a transfer of institutional/organisational knowledge emanating from a multitude of sources.

And of course, this also pertains to degree programmes and curricula. As pointed out by the Council on Higher Education:

"Within a dynamic relationship between institutional autonomy and nationally-generated standards, higher education institutions are able to design programmes that are fit for purpose, in the sense of being linked to the missions and contexts of the institutions themselves, and their capacity to be continually responsive to changes in knowledge fields and society at large." (Council on Higher Education 2011, 7)

The idea of transformation and fitness for purpose in all these areas is essentially a quest for redefining the "what" and "how" of knowledge transmission and production and the recognition of a wider set of experiences and knowledge production than the colonial worldview. Hence, 
organisational learning needs to be redefined and made inclusive of the multitude of experiences that make up the university post-mergers, and most importantly such a knowledge base needs to be consciously transferred throughout the university and its stakeholders.

\section{Fitness for transformation of places, spaces and stakeholder relationships}

Discussions on the transformation and decolonisation of the university are incomplete until they also encompass critical and creative thinking about the places and spaces in which university function, practices play out and lives fulfilled. We propose that universities should ideally be understood and opened up so that they exist and function as "transit spaces" - i.e. as spaces to which, and in which, individuals interact and move to achieve new connections in ways that fundamentally transform people and communities. By reimagining the place and space that is the university campus itself as a transit space in which a broader transformation process is facilitated and knowledge acquisition, agential development and empowerment enabled legacies of apartheid and colonialism can be ended (cf. Chasi and Rodny-Gumede 2020).

The word transit here metaphorically depicts a transformative space in which people can pass or conveyance over, or beyond, or across, or from, or through what previously existed to some other state. A view consistent with how education is itself primarily linked to the metaphor of change.

Campuses as transit places or spaces can open up to processes that conduce to individuals, societies, nations the world itself being reimagined, reconfigured, transformed and hence decolonised. They can do so by linking people to multiple and varied possibilities for sociocultural belonging, through providing extended educational, professional and social services, and by facilitating decolonised relationships between the university, the city/surrounding community and broader socio-economic policies and imperatives nationally, regionally and globally.

To this end, it is necessary that university spaces and places are changed by deliberate and non-deliberate planning and social practices, so that the legacies of apartheid and colonialism are overcome in ways that enable people to exit zones and traps of colonialism and to enter zones of freedom and liberation. Thus, it is necessary for those who think and act for the transformation of the university to remove structural, material and other barriers that would limit the extent to which the university functions optimally as a transit place and space.

This also extends to stakeholder relationships, and as with people within an organization, stakeholders and the surrounding community need to be factored in the broader transformation project of the university. The university as a transit space is shaped and identified in terms of the interrelations of members and stakeholders so that it is fundamentally different, for example, 
from the idea of the university as an ivory tower - as a fixed, demarcate, isolated and isolating container.

The key metaphor of transformation in this regard is one associated with relationships a word that depicts forms of transactions and exchange, and as such stakeholders should not only be engaged around, or informed of, organizational developments and imperatives, but need to be seen as key to the transformation project and put at the centre of decision making and the implementation of the strategies and processes of the universities transformation agenda. The definition of stakeholders must also be re-imagined and expanded to include a wider array of individuals and organisations that could influence and contribute to a broader transformation/ decolonization of the university. Most importantly, a decolonized university must literally as well as physically breakdown walls and open up to surrounding communities.

\section{TOWARDS HUMANIZING TRANSFORMATION}

Metaphors are vital to communication and to thinking about "things" because of the ways in which they activate connections that form concepts of understanding and meaning on varying levels and forms of abstraction and concreteness. Because metaphors are so vital to communication and to thinking, they also shape how humans communicatively enact cultures and how they behave within these cultures. In this sense, metaphors are fundamental to epistemic projects.

We have been interested in recognizing that colonialism and apartheid arises and is found in epistemic orders that give misanthropic value to crude distinctions. Higher education research, teaching and learning that is founded within the structures and processes of colonialism and apartheid is bound to distort, justify and extend these misanthropic and crude distinctions. It is imperative that we understand how the metaphor of transformation, applied to education, "doubles down" to emphatically state that really education moves people from one state to another so that we cease to meet and to wallow in places and spaces that are formed according to the most base distinctions that separate humans from humans and from the possibilities for cooperation that otherwise can yield more democratic, just orders.

Apartheid with its accentuated metaphors of separation, prejudice and difference, produced and continues to reproduce an episteme - a way of using, validating, thinking and hence selectively acting that politically distributes harms and goods, roughly governing and validating the cultural violence of apartheid. "Cultural violence makes direct and structural violence look even feel right - or at least not wrong" (Galtung 1990, 291). Thus the study of epistemic apartheid should not simply be about trying to understand a system of justifications and actions that relate to racial institutional colonization, it should also seek to unravel how 
epistemic apartheid involves decadent disciplining of knowledge by supporting praxes that harmfully quarantines and privileges knowledge (Rabaka 2010, 16), and importantly work towards social justice in the broadest of sense (cf. Leibowitz 2016).

The idea that apartheid is misanthropic, also indicates that the violence of apartheid is directed at misdirecting, decapitating and burying humanity itself. With reference to histories of actual decapitations and symbolic burials, Ngugi wa Thiong'o (2009) presents the narrow view that apartheid rule is aimed at killing African knowledge enterprises. However, we are committed to the broader view that apartheid as a misanthropic system works against humanity itself. It does this by drawing lines that separate people not only from knowledge itself, but also from other people.

Looking at the state of education in South Africa we see that apartheid yields increasingly decadent and deformed knowledge orders. South African schools produce students who are not ready to either take up jobs or to enter universities with good expectations of doing well. The universities of the country are constantly accused of producing graduates who are not fit for the country, even as they rise as never before on global competitiveness indexes. This is unsurprising if one takes it that one cannot reasonably separate questions of education from those of emancipation and humanization (Shor and Freire 1987, 167). And if one then grants that South Africans remain locked in a struggle against the epistemicidal violence of apartheid, impressions are that South African universities have much to do to be accepted as having transformed from instruments of apartheid to instruments fit for a democratic dispensation.

As we have noted above, there are many relational spheres to which the idea of transformation can relate. When combined, the conceptual scope that the conceptual metaphors transformation and education can together capture is extremely vast and variegated and equally so the conceptual metaphor of fitness for purpose. The semantic prosody or similar meanings of these two conceptual metaphor clusters however makes the idea of transformation of education extremely pointed and capable of emphasizing that hard agentic interventions are at hand.

While colonialism and apartheid are against the movement or change that human cooperative seeking of new and better solutions engenders, the transformation of higher education justifiably hyper-emphasizes developments or modifications that promote the realization of visions of a South African university that is relevant to the production of solutions by which South Africans may adapt to changing needs. Thus, transformation of education must be premised on fitness for purposes that work towards a humanizing development. Education humanizes by giving people capacities to pursue questions, and to meet needs, that matter to them. Transformation of education should chart the way for universities with a fitness for 
purpose that speaks to the practical, abstract and challenging questions people ask - and it should do this while addressing lived-needs in a humanizing way.

\section{NOTES}

1. Remember Mignolo's (2011) work on the meanings of modernity and as metaphor for example.

2. This is not to say that transformation debates in higher education, particularly in the South African post-apartheid context have not been researched from various angles and perspectives, not at least as seen through the work done by the South African Journal of Higher Education.

3. These ideas have not only been articulated in relation to the curricula, fitness for purpose, evidentially, also needs to be brought in to the overall operations and services rendered by the university. With regards to student accommodation for example the Department of Higher Education and Training notes importance to "ensure that students are provided with adequate, fitfor-purpose accommodation of reasonable quality, and enjoy learning and living environments that promote academic success" (Department of Higher Education and Training 2015, 2).

4. For example, metaphors that are semantically connected to form a meaningful expression without any of the metaphors necessarily assuming the position of either source (more physical reference) or target (more abstract reference). How metaphors relate as source and target domains is well illustrated with reference to Kövecses' $(2015,21)$ example of the metaphor of "life is a journey". Here "life" is the target domain and "journey" is the source domain since "life" is the subject of investigation and "journey" is the domain to which it is linked by the metaphor.

5. The importance of education for the pursuit of freedom, justice and development in Africa has long been recognised. In 1976, the Cultural Charter for Africa, one of the key documents of the Organization of African Unity, emphasised "that it is imperative to edify educational systems which embody the African values of civilization, so as to ensure the rooting of youth in African culture and mobilize the social forces in the context of permanent education". The Cultural Charter for Africa (Organisation of African Unity 1976) recalled that doing so would work towards ending political, economic, social, depersonalizing and alienating the present practices and legacies of colonial and racist domination, which include the legacies of apartheid.

6. Decolonisation itself carries different meanings as set out by De Oliveira Andreotti et al. (2015).

7. Following race-related unrest at some universities, already in 2008, the Ministerial Committee on Transformation and Social Cohesion and the Elimination of Discrimination in Public Higher Education Institutions (Report of the Ministerial Committee on Transformation and Social Cohesion and the Elimination of Discrimination in Public Higher Education Institutions 2008, 36) called for the building of inclusive institutional cultures, the promotion of compliance with generally good policy and regulatory frameworks that promote transformation and the fostering of epistemological change that manifests in curricula. But the drive to a negotiated organic, broadbased and deep-seated transformation has proven slow and difficult (Kondlo 2012). Perhaps until 2015, a feature of the difficulties of driving transformation in this environment has been that foundational norms, networks, policies, cultures and structures, set in place to a significant extent during the pre-1994 colonial and apartheid era, have tended to be stronger than less assured forces and factors for change that arose after 1994.

8. We will not attempt to unpack all the rhizomic possibilities that the intersections between ideas of transformation, education and fitness of purposes present. Suffice to say, each of the metaphorical ideas that we unpack can be read as though it is "in" another, can be seen "through" another or with the impression that it is "as-if" it is the other metaphor (cf. Kövecses 2015, 44).

9. University mission statements all tend to set out broad ideas for the overall direction of the university as well as the values underpinning such directions. Through the South African university mergers in 1996, many of the new universities formed adopted mission statements emphasizing the universities' commitment to locate the teaching and research agenda within an African context. Thus for example many mission and vision statements of South African universities of several South African universities talk to recognising South Africa as an African country located and oriented towards the African continent must be made to form strategies of 
action, i.e. "An international University of choice, anchored in Africa, dynamically shaping the future" (University of Johannesburg), "towards the African University shaping futures in the service of humanity" (University of South Africa), "UCT aspires to become a premier academic meeting point between South Africa, the rest of Africa and the world" (University of Cape Town), "Building lives, transforming a nation, advancing a continent" (University of the Witwatersrand).

\section{REFERENCES}

Bullough, R. V. 1991. Exploring personal teaching metaphors in preservice teacher education. Journal of Teacher Education 41(1): 43-51.

Bullough, R. V. and A. Gitlin. 1995. Becoming a student of teaching: Methodologies for exploring self and school context. New York: Garland Publishers.

Chasi, C. T. 2015. How to speak of ending apartheid humanities: Transformation, renaissance, metamorphosis or resurrection? Journal of Public Administration 50(2): 174-190.

Chasi, C. and Y. Rodny-Gumede. 2020. Reimagining the university as a transit place and space: A contribution to the decolonialisation debate. In The SAGE handbook of critical pedagogies, ed. B. Down and S. R. Steinberg. Newbury: SAGE. (Forthcoming).

Council on Higher Education. 2004. Founding document. $2^{\text {nd }}$ Edition. Pretoria: Council on Higher Education.

Council on Higher Education. 2011. A Framework for Qualification Standards in Higher Education. Consultation document. Pretoria: Council on Higher Education. http://www.che.ac.za/ sites/default/files/publications/Framework_November2011.pdf (Accessed 13 October 2017).

Darwin, C. 2009. On the origin of the species. Oxford: Oxford University Press.

De Oliveira Andreotti, V. and S. Stein and C. Ahenakew and D. Hunt. 2015. Mapping interpretations of decolonisation in the context of higher education. Decolonisation: Indigeneity, Education \& Society 4(1): 21-40.

Department of Education. 1997. A programme for the transformation of higher education. Education White Paper No 3, July 1997. http://www.che.ac.za/sites/default/files/publications/ White_Paper3.pdf (Accessed 6 September 2017).

Department of Higher Education and Training. 2013. White paper for post-school education and training building an expanded, effective and integrated post-school system. Department of Higher Education and Training. November, 2013. http://www.justice.gov.za/commissions/ FeesHET/docs/2013-WhitePaper-Post-SchoolEducationAndTraining.pdf (Accessed 6 September 2017).

Department of Higher Education and Training. 2015. Higher Education Act (101/1997): The Policy on the Minimum Norms and Standards for Student Housing at Public Universities 39238. 29 September 2015. Government Gazette, 897. http://www.wsu.ac.za/waltersisulu/wpcontent/uploads/2014/03/Government-Gazette-Min-Standards-Norms-for-StudentAccommodation.pdf (Accessed 13 October 2017).

Fanon, F. 1963. The wretched of the earth. New York: Grove Press.

Gallois, C. and V. J. Callan. 1991. Interethnic accommodation: The role of norms. In Contexts of accommodation: Developments in applied sociolinguistics, ed. H. Giles, J. Coupland and N. Coupland, 245-269. New York: Cambridge University Press.

Galtung, J. 1990. Cultural Violence. Journal of Peace Research 27(3): 291-305.

Kalyvas. A. 2008. Democracy and the politics of the extraordinary: Max Weber, Carl Schmitt, and Hannah Arendt. New York: Cambridge University.

Kondlo, K. 2012. "Humanities to come" and "the university without condition" - transforming the humanities in South Africa: The persistence of unresolved national agenda issues. Journal of Public Administration 47(1): 25-67. 
Kövecses, Z. 2015. Where metaphors come from: Reconsidering context in metaphor. New York: Oxford University Press.

Lakoff, G. and M. Johnson.1980. Metaphor we live by. Chicago: University of Chicago Press.

Leibowitz, B. 2016. In pursuit of socially just pedagogies in differently positioned South African higher education institutions. South African Journal of Higher Education 30(3): 219-234.

Luvalo, L. M. 2019. Relationship between transformtion and institutional culture. South African Journal of Higher Education 33(1): 184-199.

Makgoba, M. and S. Seepe. 2004. Knowledge and identity: An African vision of higher education transformation. In Towards an African identity of higher education, ed. S. Seepe, 13-58. Pretoria: Vista University and Skotville Media.

Mbembe, A. 2015. On the postcolony. Africa edition. Johannesburg: Wits Press.

Mignolo, W. 2011. The darker side of western modernity: Global futures, decolonial options. Durham: Duke University Press.

Moser, K. S. 2000. Metaphor analysis in psychology: Method, theory, and fields of application. Forum: Qualitative Social Research 1(2). www.qualitative-research.net/index.php/fqs/article/view/1090/ 2388 (Accessed 6 September 2017).

Organisation of African Unity. 1976. Cultural charter for Africa. Port Louis, Mauritius: Organisation of African Unity.

Pithouse-Morgan, K., I. Naicker, D. Pillay, L. Masinga and T. Hlao. 2016. Sink or swim?: Learning from stories of becoming academics within a transforming university terrain. South African Journal of Higher Education 30(1): 224-244.

Rabaka, R. 2010. Against epistemic apartheid: W. E. B. du Bois and the disciplinary decadence of sociology. Lanham: Lexington Books.

Report of the Ministerial Committee on Transformation and Social Cohesion and the Elimination of Discrimination in Public Higher Education Institutions. 2008. http://www.justice.gov.za/ commissions/FeesHET/docs/2008-Report-MinisterialCommittee-TransformationPHEI.pdf (Accessed 6 September 2017).

Shor, I. and P. Freire. 1987. A pedagogy for liberation dialogues on transforming education. South Hadley, M.A.: Bergin \& Garvey Publishers.

Tomasello, M. 2010. Origins of human communication. London: MIT Press.

Wa Thiong'o, N. 2009. Something torn and new: An African renaissance. New York: BasicCivitas Books. 